\title{
Facile Analytical Methods to Determine the Purity of Titanium Tetrachloride
}

\author{
Dongwook Lim, Sang-Deuk Kim, Hyungseok Kong, Daehyeon Nam, \\ Sang Eun Shim, and Sung-Hyeon Baeck 1 \\ Department of Chemistry and Chemical Engineering, Center for Design and Applications of Molecular Catalysts, \\ Inha University, Incheon 402-751, Republic of Korea
}

Correspondence should be addressed to Sung-Hyeon Baeck; shbaeck@inha.ac.kr

Received 8 February 2018; Revised 13 July 2018; Accepted 2 August 2018; Published 19 August 2018

Academic Editor: Günther K. Bonn

Copyright (C) 2018 Dongwook Lim et al. This is an open access article distributed under the Creative Commons Attribution License, which permits unrestricted use, distribution, and reproduction in any medium, provided the original work is properly cited.

\begin{abstract}
We propose a simple method to investigate both the qualitative and quantitative properties of titanium tetrachloride. The selection and concentration of the employed solvent were found to be very important in the analysis of highly reactive titanium tetrachloride $\left(\mathrm{TiCl}_{4}\right)$. Herein, we employed various concentrations of an acid solution to serve as a stabilizing medium. Qualitative analysis was performed via Fourier transform-infrared spectroscopy (FT-IR) and scanning electron microscope-energy dispersive spectroscopy (SEM-EDS). Additionally, the quantitative analysis was performed via inductively coupled plasma optical emission spectroscopy (ICP-OES). We concluded that both the qualitative and quantitative properties of titanium tetrachloride could be easily measured using a specific acidic solvent as a medium.
\end{abstract}

\section{Introduction}

Various efforts and attempts to reduce energy consumption have been applied to fields of industry and research. Endeavours with regard to improving energy efficiency within the transportation industry have attracted considerable attention toward materials. In this respect, titanium and titanium complexes have been recognized as being appropriate materials, and the consumption of titanium has been soaring across the world [1]. Pure titanium and titanium complexes have been widely used as raw materials for aerospace fuselages, airplane fuselages, and aero-engine compressor disks (requiring high strength, light weight) for high-temperature stability and corrosion resistance to enhance energy consumption efficiencies [2-6].

Besides the fields mentioned above, titanium complexes, especially titanium dioxide, are considered to be versatile metal oxides due to their wide range of applications [7-13], and high purity titanium tetrachloride is strongly required for the synthesis of titanium dioxide. In particular, size, purity, and phases of titanium dioxide are key factors affecting key properties. Various methods have been used with regard to producing ultrafine crystalline titanium dioxide, such as the sol-gel method [14, 15], sputtering [16], homogeneous precipitation in an acidic solution [17], heat treatment of aqueous titanium tetrachloride $\left(\mathrm{TiOCl}_{2}\right)$ [18], hydrolysis of titanium tetrachloride $[19,20]$, and the oxidation of titanium tetrachloride at high temperature (CVD) [21,22]. The abovementioned ways to prepare titanium dioxide generally use titanium tetrachloride as a raw material. However, it is well known that quantitative and qualitative analyses to determine the purity of $\mathrm{TiCl}_{4}$ are very difficult.

Titanium tetrachloride is an inorganic liquid transition metal halide compound at room temperature. The colour of pure titanium tetrachloride (99.9\%) is transparent, but that of crude titanium tetrachloride is light yellow. Noteworthy roles of titanium tetrachloride involve its use as a raw material for the production of pure titanium metal and titanium dioxide as mentioned above [4-6, 14, 17-22]. Naturally, the purity of titanium tetrachloride is a significant factor toward achieving high purity titanium dioxide and titanium metal. However, titanium tetrachloride is an extremely reactive compound, releasing highly corrosive gases such as hydrogen chloride $(\mathrm{HCl})$ whenever the material is exposed to water or moisture in the atmosphere $[23,24]$. For these reasons, it is difficult to analyse the purity of titanium tetrachloride. The purpose 


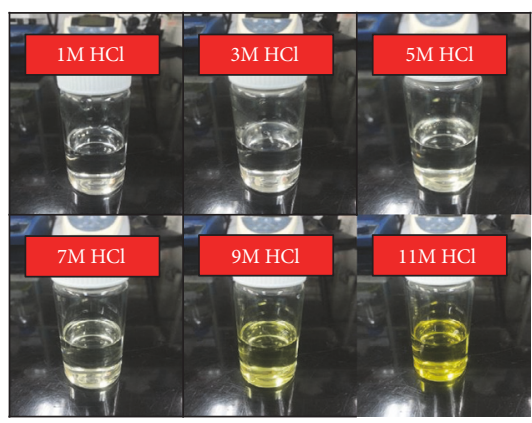

(a)

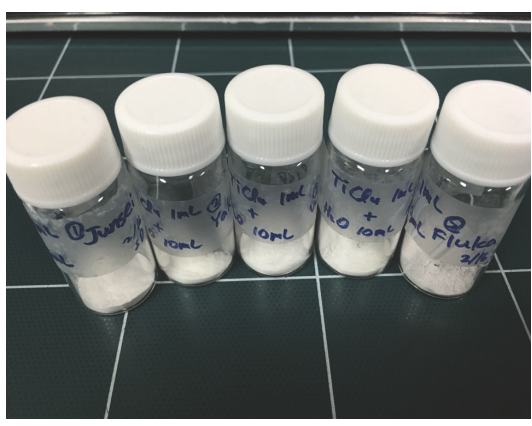

(b)

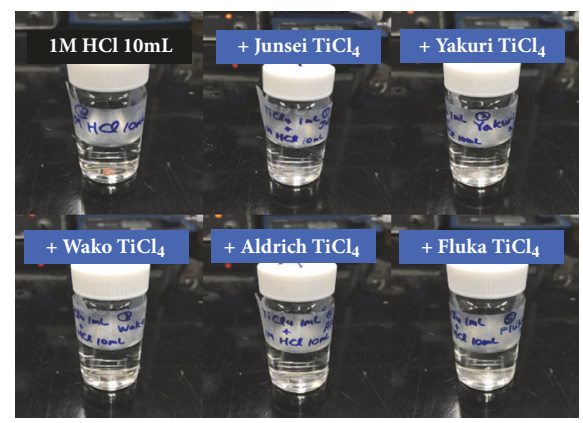

(c)

Figure 1: Stabilized titanium tetrachloride samples; (a) in various concentrated hydrochloric acid solutions, (b) hydrolyzed and calcined titanium tetrachloride (titanium oxide), and (c) titanium chloride samples and diluents prepared for ICP-OES analysis.

of this study was to optimize a purity analysis method of the highly reactive titanium tetrachloride material.

We proposed a facile analytical method to determine the purity of titanium tetrachloride. Through a stabilization of titanium tetrachloride in various concentrated acidic chloride solutions, the stabilized samples were investigated via Fourier transform-infrared spectrometry (FT-IR), energy dispersive spectroscopy (SEM-EDS) for a qualitative analysis, and inductively coupled plasma optical emission spectrometry (ICP-OES) for the quantitative analysis. With a variety of commercial titanium tetrachloride samples, impurities in titanium tetrachloride were confirmed via qualitative analysis, and purities were established via quantitative analysis.

\section{Materials and Methods}

2.1. Reagents and Apparatus. High purity titanium tetrachloride was supplied by Junsei Chemical Co., Yakuri Pure Chemicals Co., Wako Chemical Co., Aldrich chemical Co., and Fluka. All titanium tetrachloride reagents were of analytical reagent grade $(99.9 \%)$. The hydrochloric acid was purchased by Samchun Chemical Co. The used hydrochloric acid solution was of analytical reagent grade $(35 \mathrm{wt} \% \mathrm{HCl})$. To prepare the diluent for titanium tetrachloride, various concentrated hydrochloric acid $(\mathrm{HCl})$ solvent solutions were prepared by diluting the stock acid solution with DI water. A 35 wt. \% $\mathrm{HCl}$ solution was diluted with various quantities of DI water, and then $100 \mathrm{~mL}$ of $1,3,5,7,9$, and $11 \mathrm{M}$ diluted hydrochloric acid solutions was prepared.

Fourier transform-infrared vacuum spectrometer (FTIR, A Bruker VERTEX 80V) was used to analyse the impurities in titanium tetrachloride. Golden gate single reflection diamond attenuated total reflectance (ATR) was used to examine the liquid-state titanium tetrachloride samples. A Hitachi S-4300SE field emission-scanning electron microscope (FE-SEM), especially with energy dispersive spectroscopy (EDS), was used to analyse the solid-state samples. A PerkinElmer Optima 7300DV inductively coupled plasma optical emission spectrometer (ICP-OES) was used to investigate the quantities of impurities in titanium tetrachloride.
2.2. Qualitative Analysis of Titanium Tetrachloride. Liquidstate samples of stabilized titanium tetrachloride were prepared by diluting $1 \mathrm{ml}$ of titanium tetrachloride with $10 \mathrm{~mL}$ of various concentrated hydrochloric acid solutions (1, 3, $5,7,9$, and $11 \mathrm{M})$. All samples were stabilized and did not yield precipitates after 3 hours. The stabilized titanium tetrachloride samples in hydrochloric acid solution can be seen in Figure 1(a). To investigate the impurities in titanium tetrachloride via SEM-EDS, the materials were hydrolyzed in water. $1 \mathrm{~mL}$ of titanium tetrachloride was hydrolyzed with $10 \mathrm{~mL}$ of water. After the hydrolysis reaction, precipitation occurred and a white-coloured powder was synthesized at the bottom of the sample. The sample was dried at $80^{\circ} \mathrm{C}$ and calcined for 2 hours in an electric muffle furnace at $700^{\circ} \mathrm{C}$. The hydrolyzed titanium tetrachloride (titanium oxide) samples can be seen in Figure 1(b).

2.3. Quantitative Analysis of Titanium Tetrachloride. A quantitative analysis of the impurities in titanium tetrachloride was carried out by ICP-OES. In order to analyse the quantities of impurities, $1 \mathrm{~mL}$ of titanium tetrachloride was diluted to $10 \mathrm{~mL}$ of a $1 \mathrm{M}$ hydrochloric acid solution. The various titanium chloride samples diluted with $1 \mathrm{M}$ hydrochloric acid can be seen in Figure 1(c).

\section{Results and Discussion}

3.1. Qualitative Analysis of Titanium Tetrachloride. Due to the explosive reactivity of titanium tetrachloride with water or the moisture in air, the material should be stabilized and diluted [23]. The liquid phase hydrolysis reaction of titanium tetrachloride can be described as follows:

$$
\mathrm{TiCl}_{4}+2 \mathrm{H}_{2} \mathrm{O} \longrightarrow \mathrm{TiO}_{2}+4 \mathrm{HCl}
$$

A solution of hydrochloric acid is a proper stabilizer and diluent for the analysis, and the stabilization of titanium tetrachloride was performed by diluting the liquid with various concentrations of hydrochloric acid. Figure 2 shows the FT-IR spectra of the diluted solutions, and the effects of various hydrochloric acid concentrations were clearly observed. The FT-IR spectrum intensities demonstrated that a $7 \mathrm{M}$ hydrochloric acid solution was the proper diluent to 
TABLE 1: Atomic determination of impurities in titanium tetrachloride via SEM-EDS.

\begin{tabular}{lcccccccccccc}
\hline & $\mathrm{Fe}$ & $\mathrm{Al}$ & $\mathrm{Si}$ & $\mathrm{Sb}$ & $\mathrm{Cr}$ & $\mathrm{Mn}$ & $\mathrm{V}$ & $\mathrm{P}$ & $\mathrm{As}$ & $\mathrm{Ni}$ & $\mathrm{Cu}$ & $\mathrm{Sn}$ \\
\hline Detection of element & $\mathrm{O}$ & $\mathrm{O}$ & $\mathrm{O}$ & $\mathrm{O}$ & $\mathrm{O}$ & $\mathrm{O}$ & $\mathrm{X}$ & $\mathrm{X}$ & $\mathrm{X}$ & $\mathrm{X}$ & $\mathrm{X}$ & $\mathrm{X}$ \\
\hline
\end{tabular}

TABLE 2: Quantitative determination of impurities in titanium tetrachloride via ICP-OES.

\begin{tabular}{|c|c|c|c|c|c|c|c|c|c|c|c|c|}
\hline & $\mathrm{Fe}$ & $\mathrm{Al}$ & $\mathrm{Si}$ & $\mathrm{Sb}$ & $\mathrm{Cr}$ & $\mathrm{Mn}$ & $\mathrm{V}$ & $\mathrm{P}$ & As & $\mathrm{Ni}$ & $\mathrm{Cu}$ & $\mathrm{Sn}$ \\
\hline ppm & 0.11 & 0.52 & 3.99 & 41.3 & 1.86 & 0.05 & - & - & - & - & - & - \\
\hline
\end{tabular}

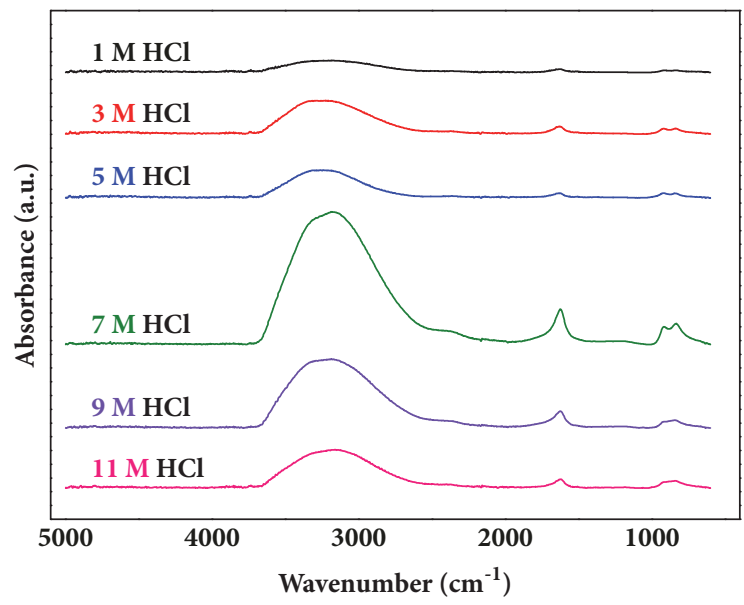

FIGURE 2: The effect of various hydrochloric acid concentrations for the qualitative analysis of titanium tetrachloride.

prepare liquid-state samples for a qualitative analysis via FT-IR spectroscopy, maximizing the peak intensities. When titanium tetrachloride was diluted with hydrochloric acid, the titanium atoms in titanium tetrachloride were ionized and existed in the form of tetravalent titanium ions [25]. Lee et al. reported that changes in $\mathrm{pH}$ values for aqueous titanium tetrachloride induced a variety of tetravalent titanium ion concentrations [18]. Hydroxyl ions had a large effect on the $\mathrm{pH}$ values and reacted with the tetravalent titanium ions, yielding precipitated titanium dioxide. Therefore, it is important to achieve acidic conditions with regard to inhibiting precipitation and maintaining the stability of titanium ions [18]. However, as the concentration of hydrochloric acid increased up to $8 \mathrm{M}$ or more, the transparent aqueous titanium tetrachloride solution changed to a white-coloured opaque solution without precipitation [18]. A $7 \mathrm{M}$ concentration of hydrochloric acid solution was optimum to preparing stabilized samples for a qualitative analysis. These results could be applied toward the analysis of various commercial titanium tetrachloride samples, as shown in Figure 3. There were slight discrepancies in intensities, though all the band regions exhibited the same tendencies.

As shown in Figure 3, bands in the region of 3600$2500 \mathrm{~cm}^{-1}$ for the spectra of diluted titanium tetrachloride in aqueous solution were due to $\mathrm{Ti}-\mathrm{OH}$ and $-\mathrm{OH}$ vibrations [26]. The band at $1642 \mathrm{~cm}^{-1}$ corresponded to $\mathrm{H}-\mathrm{O}-\mathrm{H}$ and $\mathrm{Ti}-\mathrm{H}_{2} \mathrm{O}$ [27]. The IR spectrum around $820 \mathrm{~cm}^{-1}$ was observed to correspond to the $\mathrm{TiOCl}_{2}$ band as a by-product of the

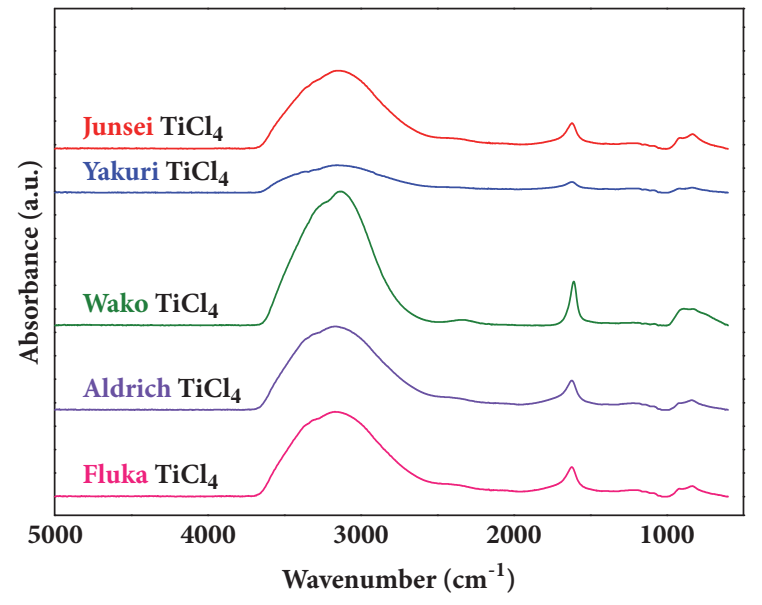

FIGURE 3: FT-IR analysis of various commercial titanium tetrachloride samples via dilution in $7 \mathrm{M}$ hydrochloric acid.

hydrolysis of titanium tetrachloride and water [17, 28, 29]. However, it is well known that other elements ( $\mathrm{Fe}, \mathrm{Si}, \mathrm{V}, \mathrm{Sb}$, $\mathrm{Mn}$, and $\mathrm{Cr}$ ) exist as impurities in titanium tetrachloride. Due to the low concentrations of impurities in titanium tetrachloride, the impurities could not be analysed via FT-IR spectroscopy.

To further investigate the impurities in titanium tetrachloride, SEM-EDS analysis was employed to perform a qualitative analysis as shown in Table 1. Following the hydrolysis and calcination of titanium tetrachloride, a white-coloured titanium dioxide powder was prepared for EDS. While impurities such as $\mathrm{Fe}, \mathrm{Al}, \mathrm{Si}, \mathrm{Sb}, \mathrm{Cr}$, and $\mathrm{Mn}$ were detected in titanium tetrachloride, other general impurities such as $\mathrm{V}$, $\mathrm{P}, \mathrm{As}, \mathrm{Ni}, \mathrm{Cu}$, and $\mathrm{Sn}$ were not found.

3.2. Quantitative Analysis of Titanium Tetrachloride. From the qualitative analysis results, various impurities in titanium tetrachloride were determined. Quantitative analysis was performed to determine the quantity of impurities in titanium tetrachloride via ICP-OES as shown in Table 2. The experiments were carried out three times, and the standard errors were less than 3\%. All data in Tables 2 and 3 represent mean values of three analyses. As mentioned in the experimental section, the titanium tetrachloride samples were prepared via dilution in $1 \mathrm{M}$ hydrochloric acid. The results of the quantitative analysis indicated only cationic weights of impurities, which were composed of metal halides or metalloid halides. For these reasons, accurate weights of 
TABLE 3: Purities of commercial titanium tetrachlorides.

\begin{tabular}{lccccc}
\hline Company & Junsei & Yakuri & Wako & Aldrich & Fluka \\
\hline Purity (\%) & 99.92 & 99.93 & 99.92 & 99.91 & 99.92 \\
\hline
\end{tabular}

the impurities should be calculated with the addition of elemental chlorine. For instance, Fe existed in the form of $\mathrm{FeCl}_{3}$ within titanium tetrachloride. The atomic weight of $\mathrm{Fe}$ was $0.11 * 10^{-6} \mathrm{~g}$ and that of $3 \mathrm{Cl}^{-}$was $0.21 * 10^{-6} \mathrm{~g}$. Thereby, $0.32 * 10^{-6} \mathrm{~g}$ of $\mathrm{FeCl}_{3}$ existed in titanium tetrachloride. Undergoing this process, the purity of titanium tetrachloride was determined by subtracting the mass of all the impurities within the prepared sample. As shown in Table 3, the purity values of titanium tetrachloride supplied by Junsei Chemical Co., Yakuri, Wako, Sigma Aldrich, and Fluka were 99.92, 99.93, 99.92, 99.91, and 99.92\%, respectively. The results were consistent with the purity values reported by the titanium tetrachloride manufacturers.

\section{Conclusions}

Titanium tetrachloride samples for qualitative analysis were diluted with $7 \mathrm{M}$ hydrochloric acid due to imparting the highest stability and yielding the highest intensity of FT-IR. Few impurities were detected, while the following impurities were not detected at any level: Fe, Si, V, Sb, Cr, and $\mathrm{Mn}$. Another qualitative analysis (EDS) was utilized to determine the impurities through the hydrolysis of titanium tetrachloride. The results revealed that impurities such as $\mathrm{Fe}, \mathrm{Al}, \mathrm{Si}, \mathrm{Sb}$, $\mathrm{Cr}$, and $\mathrm{Mn}$ existed in titanium tetrachloride. A quantitative analysis was also performed to know the concentrations of impurities by the qualitative analysis (ICP-OES). The analysis results indicated that the impurities in titanium tetrachloride existed at ppm concentrations. According to the results, the purity of titanium tetrachloride was almost 99.91 99.93\%. This study established a facile analytical method to determine the purity of titanium tetrachloride via diluting and stabilizing with hydrochloric acid.

\section{Data Availability}

The data that support the findings of this study are available from the corresponding author upon reasonable request.

\section{Conflicts of Interest}

The authors declare that there are no conflicts of interest regarding the publication of this paper.

\section{Acknowledgments}

This work was supported by Inha University Research Grant.

\section{References}

[1] L. Zhang, X. Wang, and X. Qu, "Application status and market analysis of non-aero titanium in China," Key Engineering Materials, vol. 520, pp. 8-14, 2012.
[2] C. Li, M. Zhu, N. Wang, X. Lu, and S. Cheng, "Application of titanium alloy in airplane," Xiyou Jinshu / Chinese Journal of Rare Metals, vol. 33, no. 1, pp. 84-91, 2009.

[3] S. Aixue, W. Qingru, and L. Xingwu, "Research and application of high-strength titanium alloys used in airplane structure," Chinese Journal of Rare Metals, vol. 1, p. 70, 2004.

[4] Y. G. Zhou, W. D. Zeng, and H. Q. Yu, "An investigation of a new near-beta forging process for titanium alloys and its application in aviation components," Materials Science and Engineering: A Structural Materials: Properties, Microstructure and Processing, vol. 393, no. 1-2, pp. 204-212, 2005.

[5] Z. M. Hu and T. A. Dean, "Aspects of forging of titanium alloys and the production of blade forms," Journal of Materials Processing Technology, vol. 111, no. 1-3, pp. 10-19, 2001.

[6] P. Doorbar, M. Dixon, and A. Chatterjee, "Aero-engine titanium from alloys to composites," Materials Science Forum, vol. 618, pp. 127-134, 2009.

[7] A. Fujishima, T. N. Rao, and D. A. Tryk, "Titanium dioxide photocatalysis," Journal of Photochemistry and Photobiology C: Photochemistry Reviews, vol. 1, no. 1, pp. 1-21, 2000.

[8] A. Fujishima and X. Zhang, "Titanium dioxide photocatalysis: present situation and future approaches," Comptes Rendus Chimie, vol. 9, no. 5-6, pp. 750-760, 2006.

[9] G. Li Puma, A. Bono, and J. G. Collin, "Preparation of titanium dioxide photocatalyst loaded onto activated carbon support using chemical vapor deposition: a review paper," Journal of Hazardous Materials, vol. 157, no. 2-3, pp. 209-219, 2008.

[10] M. Pelaez, N. T. Nolan, S. C. Pillai et al., "A review on the visible light active titanium dioxide photocatalysts for environmental applications," Applied Catalysis B: Environmental, vol. 125, pp. 331-349, 2012.

[11] J. H. Braun, “Titanium dioxide: a review, JCT," Journal of Coatings Technology, vol. 69, no. 868, pp. 59-72, 1997.

[12] U. Gesenhues, "Influence of titanium dioxide pigments on the photodegradation of poly(vinyl chloride)," Polymer Degradation and Stability, vol. 68, no. 2, pp. 185-196, 2000.

[13] R. E. Day, "The role of titanium dioxide pigments in the degradation and stabilisation of polymers in the plastics industry," Polymer Degradation and Stability, vol. 29, no. 1, pp. 73-92, 1990.

[14] D.-S. Lee and T.-K. Liu, "Preparation of $\mathrm{TiO}_{2}$ sol using $\mathrm{TiCl}_{4}$ as a precursor," Journal of Sol-Gel Science and Technology, vol. 25, no. 2, pp. 121-136, 2002.

[15] W. Zhang, K. Wang, Y. Yu, and H. He, " $\mathrm{TiO}_{2} / \mathrm{HZSM}-5$ nanocomposite photocatalyst: $\mathrm{HCl}$ treatment of NaZSM-5 promotes photocatalytic degradation of methyl orange," Chemical Engineering Journal, vol. 163, no. 1-2, pp. 62-67, 2010.

[16] W. Zhang, K. Wang, S. Zhu, Y. Li, F. Wang, and H. He, "Yttriumdoped $\mathrm{TiO}_{2}$ films prepared by means of DC reactive magnetron sputtering," Chemical Engineering Journal, vol. 155, no. 1-2, pp. 83-87, 2009.

[17] S.-J. Kim, S.-D. Park, Y. H. Jeong, and S. Park, "Homogeneous precipitation of $\mathrm{TiO}_{2}$ ultrafine powders from aqueous $\mathrm{TiOCl}_{2}$ solution," Journal of the American Ceramic Society, vol. 82, no. 4, pp. 927-932, 1999. 
[18] J. H. Lee and Y. S. Yang, "Effect of $\mathrm{HCl}$ concentration and reaction time on the change in the crystalline state of $\mathrm{TiO}_{2}$ prepared from aqueous $\mathrm{TiCl}_{4}$ solution by precipitation," Journal of the European Ceramic Society, vol. 25, no. 16, pp. 3573-3578, 2005.

[19] N.-G. Park, G. Schlichthörl, J. van de Lagemaat, H. M. Cheong, A. Mascarenhas, and A. J. Frank, "Dye-sensitized $\mathrm{TiO}_{2}$ solar cells: structural and photoelectrochemical characterization of nanocrystalline electrodes formed from the hydrolysis of $\mathrm{TiCl}_{4}$," The Journal of Physical Chemistry B, vol. 103, no. 17, pp. 33083314, 1999.

[20] W. Zheng, X. Liu, Z. Yan, and L. Zhu, "Ionic liquid-assisted synthesis of large-scale $\mathrm{TiO}_{2}$ nanoparticles with controllable phase by hydrolysis of $\mathrm{TiCl}_{4}$," ACS Nano, vol. 3, no. 1, pp. 115122, 2009.

[21] B. Karlemo, P. Koukkari, and J. Paloniemi, "Formation of gaseous intermediates in titanium(IV) chloride plasma oxidation," Plasma Chemistry and Plasma Processing, vol. 16, no. 1, pp. 59-77, 1996.

[22] K. L. Sietering and G. L. Griffin, "Growth kinetics of CVD TiO influence of carrier gas," Journal of the Electrochemical Society, vol. 137, no. 4, pp. 1206-1208, 1990.

[23] T. Kapias and R. F. Griffiths, "Accidental releases of titanium tetrachloride $\left(\mathrm{TiCl}_{4}\right)$ in the context of major hazards-Spill behaviour using REACTPOOL," Journal of Hazardous Materials, vol. 119, no. 1-3, pp. 41-52, 2005.

[24] T. Kapias, R. F. Griffiths, and C. Stefanidis, "REACTPOOL: a code implementing a new multi-compound pool model that accounts for chemical reactions and changing composition for spills of water reactive chemicals," Journal of Hazardous Materials, vol. 81, no. 1-2, pp. 1-18, 2001.

[25] J. Saji, K. J. Saji, and M. L. P. Reddy, "Liquid-liquid extraction of tetravalent titanium from acidic chloride solutions by bis $(2,4,4$ trimethylpentyl)phosphinic acid," Solvent Extraction and Ion Exchange, vol. 18, no. 5, pp. 877-894, 2000.

[26] Y.-F. Chen, C.-Y. Lee, M.-Y. Yeng, and H.-T. Chiu, "The effect of calcination temperature on the crystallinity of $\mathrm{TiO}_{2}$ nanopowders," Journal of Crystal Growth, vol. 247, no. 3-4, pp. 363-370, 2003.

[27] M. S. Corobea, M. Stoenescu, M. Miculescu et al., "Titanium functionalizing and derivatizing for implantable materials osseointegration properties enhancing," Digest Journal of Nanomaterials and Biostructures, vol. 9, no. 4, pp. 1339-1347, 2014.

[28] L. A. Bruno and B. C. Beard, "Application of infrared spectroscopy for the determination of $\mathrm{TiOCl}_{2}$ in $\mathrm{TiCl}_{4}$," Applied Spectroscopy, vol. 51, no. 1, pp. 131-132, 1997.

[29] D. T. Tsekhovol'skaia, T. A. Zavaritskaia, G. S. Denisov, and V. M. Chulanovskii, "The application of infra-red spectroscopy to the analysis of titanium tetrachloride," Spectrochim Acta, vol.16, no. 5, pp. 547-550, 1960. 

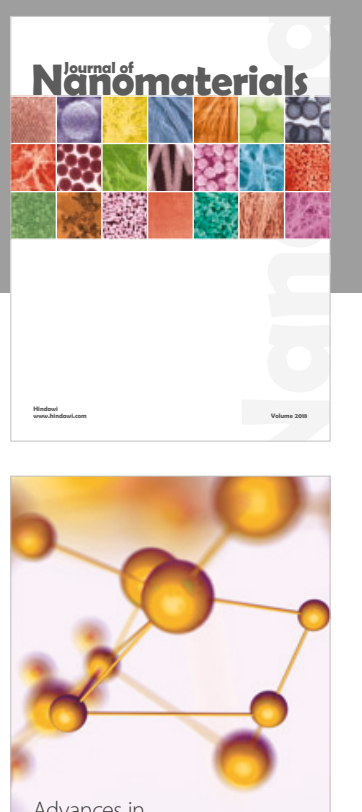

Physical Chemistry
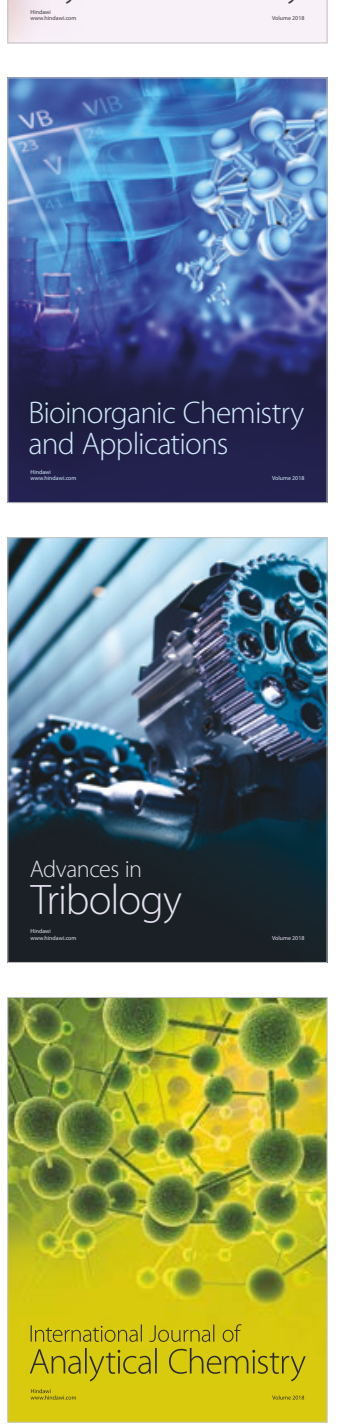

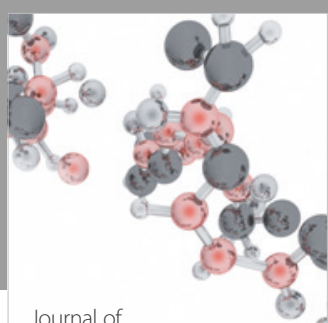

Analytical Methods

in Chemistry

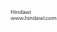

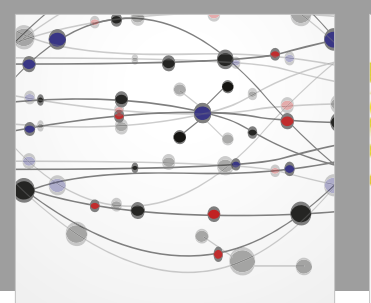

The Scientific World Journal

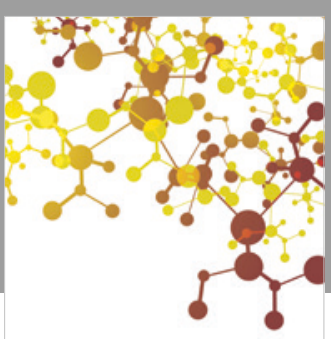

Journal of

Applied Chemistry
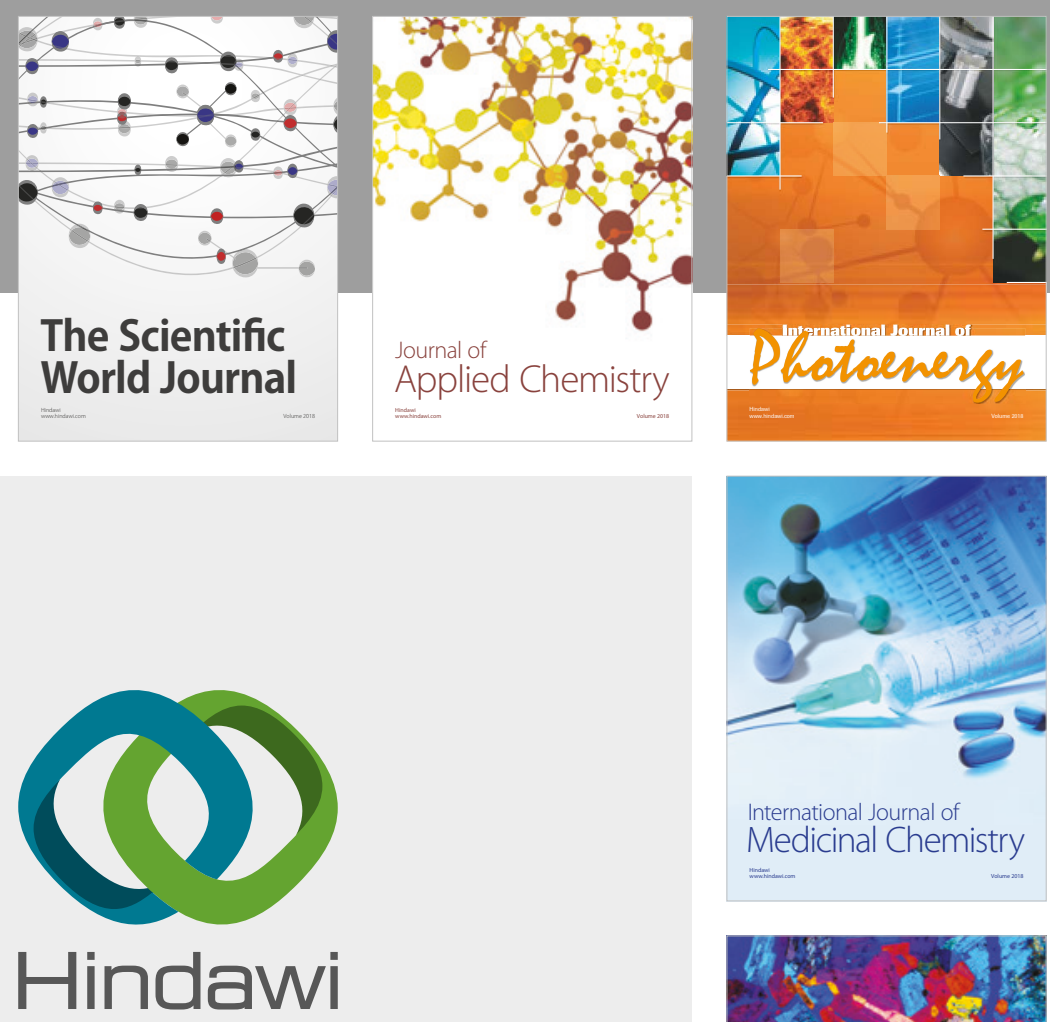

Submit your manuscripts at

www.hindawi.com
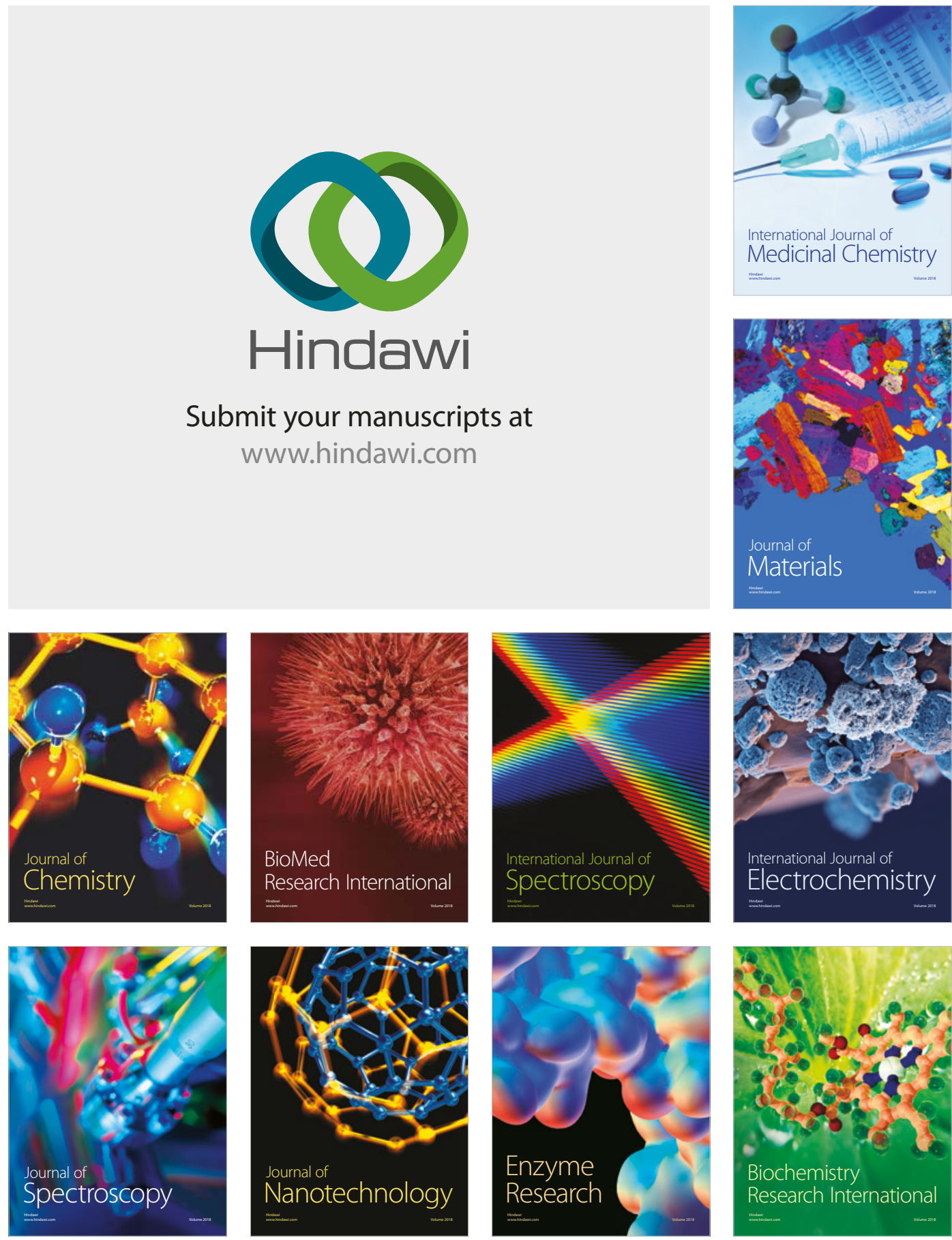
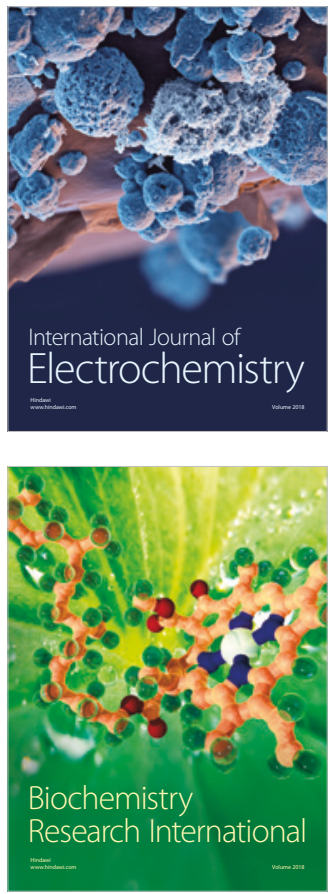